\title{
Innovative Management in Distance Education-The Importance of Monitoring Meetings in a Postgraduate Course in the Multidisciplinary Team Perspective
}

\author{
Marize Lyra Silva Passos, Vanessa Battestin Nunes \\ Federal Institute of Education, Science and Technology of Espírito Santo, Vitória, Brazil
}

\begin{abstract}
The focus of this study was to analyze, in the view of the multidisciplinary team, the importance given to meetings to support the implementation of the subjects in a postgraduate course offered at a distance. As a technical procedure, this study used the survey research method, and data collection of the opinion of the multidisciplinary team was performed using a questionnaire. The research had a quantitative approach with a qualitative bias that sought to transform reality into data to allow its interpretation. After analyzing the data, it became clear that the multidisciplinary team considers the meetings as efficient and effective to improve the performance of these disciplines and generate an improvement of the interaction of the multidisciplinary team.
\end{abstract}

Keywords: management in distance education, innovation, interaction

\section{Introduction}

Distance learning has emerged as the main phenomenon of changes in education in the early 21 st century. It brings changes in the learning process and also in the way teachers manage these new types of courses, since the method implemented in the various levels of education presents innovative character, as pointed out in several studies (Rumble, 2003; Nunes, 2009; Souza \& Faria, 2013).

Nunes (2009) stated that, in recent decades, the implementation of a new generation of courses offered at a distance "[...] began to open possibilities to promote educational opportunities for large populations" (p. 3). This new generation of courses no longer only focuses on quantitative criteria, but mainly on the basis of quality, flexibility, freedom, and criticism notions. These in turn have their own characteristics and complexities that "[...] now requires new education system management processes" (Bernardi, Daudt, \& Behar, 2013, p. 135).

Peters (2004) pointed out that offering courses in the distance education mode involves the application of industrial processes in conveying instruction, among these we can highlight systematic planning; specialization of the work team; production of own materials; and automation, standardization, quality control, and use of modern communication technologies. From this perspective, the Federal Institute of Education, Science and Technology of Espírito Santo (IFES) offers distance learning courses for over nine years, seeking with his

Marize Lyra Silva Passos, D.Sc., professor, Reference Center for Teacher Education and Distance Education, Federal Institute of Education, Science and Technology of Espírito Santo.

Vanessa Battestin Nunes, D.Sc., professor, Reference Center for Teacher Education and Distance Education, Federal Institute of Education, Science and Technology of Espírito Santo. 
research body to test the use of new processes to support teaching and management of distance education.

The course focus of this study was the postgraduate course in computers in education (PCE), which is managed by a multidisciplinary team consisting of course coordinator, tutoring coordinator, instructional designer, pedagogue, teachers, and tutors (Nobre, Nunes, Gava, \& Albernaz, 2011). To ensure that the courses offering process occurs effectively and efficiently, and ensure the integration of process players, the ongoing staff proposed the establishment of three control meetings for each subject: the initial, intermediate, and final. Thus, this research aimed to analyze, in the view of the multidisciplinary team, the importance attached to these meetings.

\section{Management in Distance Education}

With the growth in the offer of distance education, educational institutions began to live with new ways to view and organize education, and therefore, seek to identify and develop academic processes geared to this new reality in the educational and administrative point of view. According to Bernardi et al. (2013):

[...] The management of distance education is linked to the paradigm of the network society. In this it is required of the institutions to adopt policies and flows that enable and qualify the relationships inside. From these actions, we propose a new concept of educational organization that requires decentralized, participatory, integrated and interdependent functions. (pp. 135-136)

Management is a process comprising the planning, organization, coordination, and control of decision-making actions aiming to develop activities in an efficient and effective way (Sartori \& Roesler, 2005; Rumble, 2003; Lacombe \& Heilborn, 2003).

On the other hand, educational management is a specific action that aims to organize and mobilize the human and material conditions, available and necessary to the success of the educational process that needs to be characterized as democratic and participatory. It is assumed responsibility and active participation of all stakeholders seeking to increasingly significant educational outcomes as a collective commitment (Bernardi et al., 2013).

Education management, specifically the management of distance education, seeks guidance for strengthening relations within a new concept of educational organization based on physical distance between students, faculty, and institution, which demand management of decentralized, participatory, interdependent, but also integrated functions.

In this context, it is noted "[...] the need for an adequate and differentiated management, mainly related to the design aspects, teaching, planning and communication strategies [...]” (Bernardi et al., 2013, p. 137).

\section{Management Innovation in Distance Education}

The significant growth of organizations offering distance education courses has caused teachers and administrators to become aware of the need to reflect on how to organize and manage these systems, although it is not a simple task, as it involves a large number of players: students, teachers, tutors, managers, technical staff, infrastructure, the institution itself, among others, which requires managers' careful attention to the decision-making (Souza \& Faria, 2013; Rumble, 2003).

As seen previously:

[...] Distance education management requires an understanding of the variables that make up the whole of your system. Knowledge about your coverage can facilitate the search for innovative, creative and economically viable solutions. On the other hand, poses challenges for managers. (Bernardi et al., 2013, p. 138) 
Due to the characteristics and complexity of distance education, the innovation process in its management is natural and expected, and permeates various degrees of novelty and complexity inherent in this type of education. "[...] So that it often requires the development and adaptation of solutions and models to the specific organizational context considered, reflecting the need for the innovation process to be investigated in this context" (Souza \& Faria, 2013, pp. 314-315).

All previous arguments support the idea that research on innovation in the context of distance education is important, since the dynamics of innovation can raise reflections upon improvement initiatives in the management of these systems. In order to achieve this purpose, this article presents and discusses innovative management experience that was due to the implementation of meetings - initial, intermediate, and final — which are designed to monitor and assist in the correction of management of the course subjects offered.

\section{The Initial, Intermediate, and Final Meetings}

In IFES, the postgraduate courses have a managing body, the course collegiate, who are responsible for deciding on matters related to teaching and research developed in the respective course, but do not perform a thorough monitoring of each discipline. In PCE, it is worth highlighting the implementation of the initial, intermediate, and final meetings promoted by the coordination team to facilitate the achievement of efficiency and effectiveness in the disciplines offering process.

These meetings can be in person or online and occur between teacher and distance tutors, with the support of a member of the coordination team. For each meeting, the teacher, with the support of the classroom and distance tutors, is responsible for the completion of a minutes that is available to be consulted by the coordination team, which facilitates the assimilation of the topics discussed (Nunes, Nobre, \& Passos, 2013).

In the case of PCE, subjects are offered in pairs. So, there is a whole interdisciplinary planning and meetings of concomitant subjects occur together, so there is a better understanding of the interdisciplinary approach and its implementation by tutors in the process of teaching and learning. Meetings are attended by teachers and tutors from both disciplines, resulting in the completion of two minutes, one for each discipline.

The initial meeting aims to present the discipline, its methodology and evaluation activities, and the correction criteria. This should occur at least two weeks before the start of the course. The pedagogue participates in the meeting in addition to the teachers and tutors (Passos, Nobre, \& Nunes, 2014).

The intermediate meeting aims to adjust the implementation of the discipline, especially with respect to tutoring activity. In addition to teachers and tutors, the tutoring coordinator also participates. It should take place in half the time expected for the discipline duration, enabling some intervention before completion of the course (Nunes et al., 2013).

The final meeting is aimed at the closing of the grades and the evaluation of the implementation of the discipline, with notes on how to work best the following disciplines and also in future editions of these same disciplines. In addition, it is done the survey of good practice and the setting of dates for the closing of pending issues. In addition to teachers and tutors, the course coordinator also participates. It must occur at the end of the course (Nunes et al., 2013).

\section{Method}

This was an applied and exploratory study that sought to analyze and increase knowledge about the effectiveness of initial, intermediate, and final meetings from the point of views of the multidisciplinary team. 
As for the approach, it was a quantitative research with a qualitative bias that sought to transform reality into data allowing its interpretation. Since its qualitative bias aimed at giving voice to the survey panel as their views on the subject, and with respect to the technical procedure used to evaluate the opinion of the panel, the study used the survey research method, which seeks to obtain data or information about characteristics, actions, or opinions of a certain group of people. To obtain data, it was applied to the multidisciplinary team a questionnaire on the effectiveness of meetings. The target audience of this research was the 23 members of the multidisciplinary team, of which 15 agreed to participate, which is equivalent to $65 \%$ of the group studied.

To assess the importance attached to PCE meetings, we used a questionnaire composed of 26 questions divided into two parts: participant identification and data about meetings. The second part was divided into three constructs to facilitate statistical analysis - review of the initial meeting, review of the intermediate assembly, and review of the final meeting - each of which has five statements about the meeting's contribution to the successful implementation of the course, and they were evaluated on a score ranging from 1 to 5 , with 1 being little and 5 being great contribution. In addition to the five statements, each construct has an open question where the participants can opine freely about the meeting.

The questionnaire was evaluated by three experts in the field and then its consistency was measured using Cronbach's $\alpha$. The results were better than expected $(\alpha \geq 0.55)$, which indicates a good internal consistency of the constructs (see Table 1).

Table 1

Analysis of the Consistency of the Questionnaire Constructs

\begin{tabular}{lll}
\hline Construct & Number of items & Cronbach's $a$ \\
\hline 1. Review of the initial meeting & 6 & 0.950 \\
2. Review of the intermediate meeting & 6 & 0.936 \\
3. Review of the final meeting & 6 & 0.737 \\
\hline
\end{tabular}

Note. Source: Analysis performed in Statistical Package for the Social Sciences (SPSS) Version 22.

The questionnaire was built using Google Forms and sent by email to the participants. They had the option after reading the "free and informed consent term" to respond to the questionnaire or not.

\section{Results and Discussion}

Of the members of the multidisciplinary team that participated in the study, 12 are women and 3 are men; they are aged more than 31 years, and $78 \%$ aged more than 41 years; they have more than three years of experience on the course and $71 \%$ of them have some academic background in education. After analyzing the socio-demographic data, an analysis of the constructs was carried out, and therefore, we calculated the averages, medians, and standard deviations.

The analysis of Construct 1 (see Table 2), which refers to the initial meeting, shows that the average of the determinants is high, all above 4 , and the variability was low. The item guidance on how to act in the discipline was the most valued, followed by understanding the dynamic of the discipline. As these are directly linked to the actions expected of educational management, they have the function of organizing and mobilizing human and material conditions to achieve success in the educational process (Sartori \& Roesler, 2005; Rumble, 2003; Lacombe \& Heilborn, 2003). 
Table 2

Median Concerning the General Perception of the Construct Initial Meeting

\begin{tabular}{llllll}
\hline Initial meeting $(N=15)$ & Minimum & Maximum & $\begin{array}{l}\text { Mean } \pm \text { Standard } \\
\text { deviation }\end{array}$ & $\begin{array}{l}\text { Coefficient of } \\
\text { variation }\end{array}$ & $\begin{array}{l}\text { Median } \\
\text { Understand the dynamics of the discipline }\end{array}$ \\
Understand the tasks to be performed in the discipline & 2.0 & 5.0 & $4.533 \pm 0.8338$ & 0.695 & 5.00 \\
Facilitates the team integration & 2.0 & 5.0 & $4.333 \pm 0.8165$ & 0.667 & 4.00 \\
Guidance on how to act during the discipline & 3.0 & 5.0 & $4.467 \pm 0.9904$ & 0.981 & 5.00 \\
Team suggestions are heeded & 2.0 & 5.0 & $4.733 \pm 0.5936$ & 0.352 & 5.00 \\
\hline
\end{tabular}

Note. Source: Analysis performed in SPSS Version 22.

These results confirm that the survey participants mostly agree that the initial meeting is important. But these did not have the participation of all the guests, which creates any dissatisfaction, as is clear in the quotes of some participants:

Sadly, we did not got a good quorum at meetings causing important information to be lost by tutors, which makes colleagues to have different procedures or do not understand the proposed task. (Teacher 5)

The meeting is very important for sure. But not all attend. The absence of a member is very noticeable. And, it depends on the conscience of each individual, because participation is encouraged. (Teacher 15)

In Construct 2 analyses (see Table 3), with respect to the intermediate meeting, it is noted that the average of the determinants was slightly lower than those obtained in Construct 1, but was still greater than or equal to 4 and with smaller variances.

Table 3

Median Regarding the Perception of the Construct Intermediate Meeting

\begin{tabular}{llllll}
\hline Intermediate meeting $(N=15)$ & Minimum & Maximum & $\begin{array}{l}\text { Mean } \pm \\
\text { deviation }\end{array}$ & $\begin{array}{c}\text { Standard Coefficient of } \\
\text { variation }\end{array}$ & \begin{tabular}{l} 
Median \\
\hline To check discipline progress
\end{tabular} \\
Learn more about the class & 2.0 & 5.0 & $4.2 \pm 0.9411$ & 0.886 & 4.00 \\
Development and problems of the class & 2.0 & 5.0 & $4.067 \pm 0.9612$ & 0.924 & 4.00 \\
Interdisciplinary occurrence & 3.0 & 5.0 & $4.267 \pm 0.5936$ & 0.352 & 4.00 \\
Correction in the implementation of the discipline & 3.0 & 5.0 & $4.067 \pm 0.7988$ & 0.638 & 4.00 \\
\hline
\end{tabular}

Note. Source: Analysis performed in SPSS Version 22.

The most valued item in the intermediate meeting was the opportunity to correct the course of the discipline, which is quoted by Nunes et al. (2013) as the main purpose of the meeting. For the subjects, the absence of some participants at the meeting has impaired the effectiveness of it. Yet, they consider it equally important and think it could be done online.

It is important because the problems are raised and the issues fixed. (Teacher 3)

In fact, I do not see much point to that meeting, I think the adjustments in the course and monitoring are needed yes, but that we can do via e-mail. Or, not an in-person meeting, but a scheduled meeting via Skype to exchange ideas on the progress of the class and activities, this way we can communicate and check situations that can be solved. (Tutor 7)

In Construct 3 (see Table 4), which refers to the final meeting, it appears that the determinants average was very close to those obtained in Construct 1 and also had small variances. The items with higher average were to solve academic pending issues and to support the next openings of the discipline with information, these actions related to management of distance education. 
Table 4

\section{Medians Concerning the General Perception of the Construct Final Meeting}

\begin{tabular}{|c|c|c|c|c|c|}
\hline Final meeting $(N=15)$ & Minimum & Maximum & $\begin{array}{l}\text { Mean } \pm \text { Standard } \\
\text { deviation }\end{array}$ & $\begin{array}{l}\text { Coefficient of } \\
\text { variation }\end{array}$ & Median \\
\hline Solve administrative pending issues & 3.0 & 5.0 & $4.333 \pm 0.6172$ & 0.381 & 4.00 \\
\hline Solve academic pending issues & 3.0 & 5.0 & $4.6 \pm 0.6325$ & 0.400 & 5.00 \\
\hline Reflections on the achieved results & 2.0 & 5.0 & $4.4 \pm 0.9103$ & 0.829 & 5.00 \\
\hline Feedback for the next disciplines & 1.0 & 5.0 & $4.333 \pm 1.1127$ & 1.238 & 5.00 \\
\hline Subsidies for next course offerings & 4.0 & 5.0 & $4.733 \pm 0.4577$ & 0.210 & 5.00 \\
\hline
\end{tabular}

Note. Source: Analysis performed in SPSS Version 22.

One can see that for the research participants, the final meeting is as important as the others. It is also clear that the absence of some participants affects the expected results and several participants think that the same could be done in online form, as seen in the following statements:

In my opinion, it is the most important of all, for in it, we learn and solve issues for subsequent classes/courses. (Professor 3)

That is truly an essential meeting so that tutors can expose problems among students and which may yet be addressed in time, how to avoid failures and other pending situations. One way of integrating all to evaluate the discipline, even enabling an analysis to be used by the next editions. (Tutor 6)

We still have difficulties to finish the discipline in that meeting. I think a more direct work with tutors and teachers in order to reach the final evaluation with all results concluded the final meeting gets more productive. (Tutor 8)

Some team members highlight the initial meeting, other intermediate, but it is evident the importance given to these three moments for reflection, exchange of experiences, and the search for solutions together, which according to Bernardi et al. (2013) should be a concern of managers of distance learning courses, and aimed at boosting the relations within a new concept of educational organization seeking to achieve participation and integration between those involved in the educational process.

In the case of the PCE course, the subjects are planned and executed in an interdisciplinary way, such meetings positively impact the teaching and learning process, ensuring greater integration of the team.

\section{Conclusion}

The realization of support meetings is an innovative practice for the management of distance education, since often this practice is not common given this mode characteristics.

This practice has been tested and evaluated by the team of PCE for four years and, as seen, for the multidisciplinary team, its realization is effective in improving the performance of subjects and facilitating interaction among staff, allowing with their feedbacks improvements in the course subjects execution, as well as a better understanding of the classes for planning future disciplines, improving the interaction of the multidisciplinary team and the interdisciplinary.

It is worth mentioning here that most think these meetings are impaired when there is the absence of some of the team members and also that some of them could be carried out online, which could guarantee greater participation.

The research subjects point out that those moments are also important to promote reflection on the pedagogical practice of teachers, tutors, and the team as a whole. 


\section{References}

Bernardi, M., Daudt, S. D., \& Behar, P. A. (2013). Domínio da gestão em educação a distância (Management domain in distance education). In P. A. Behar (Ed.), Competências em educação a distância (Expertise in distance education) (pp. 135-149). Porto Alegre: Penso.

Lacombe, F. J. M., \& Heilborn, G. L. J. (2003). Administração: Princípios e tendências (Administration: Principles and trends). São Paulo: Saraiva.

Mill, D., Brito, N. D., Silva, A. R., \& Almeida, L. F. (2010). Gestão da educação a distância (EaD): Noções sobre planejamento, organização, direção e controle da $\mathrm{EaD}$ (Management of distance education: Principles of management, organization, direction, and control). Revista Vertentes, 35.

Nobre, I. A., Nunes, V. B., Gava, T. B. S., \& Albernaz, J. M. (2011). Desafios e conquistas no planejamento de um curso multi, inter e transdisciplinar a distância (Challenges and achievements in planning a multi course, inter- and transdisciplinary distance). Paper presented at The $10^{\circ}$ Encontro de Pesquisa em Educação da Região Sudeste.

Nunes, I. B. (2009). A história da EaD no mundo (The history of distance education in the world). In F. M. Litto, \& M. M. M. Formiga (Eds.), EaD: O estado da arte (Distance education: The state of the art) (pp. 3-8). São Paulo: Pearson Education do Brasil.

Nunes, V. B., Nobre, I. A., \& Passos, M. L. S. (2013). Um modelo de gestão participativa—Processos de interação e comunicação da equipe multidisciplinar com Foco na melhoria do ensino-aprendizado (A participatory management model of interaction and communication with the multidisciplinary team focus on improving teaching and learning processes). Paper presented at The $19^{\circ}$ Congresso Internacional ABED de Educação a Distância, Salvador.

Passos, M. L. S., Nobre, I. A. M., \& Nunes, V. B. (2014). Regulação em um processo de avaliação formativa em um curso de pós-graduação ofertado a distância (Regulation in a formative evaluation process in a graduate course offered distance). Paper presented at The XI Congresso Brasileiro de Ensino Superior a Distância, Florianopolis.

Peters, O. (2004). A educação a distância em transição: Tendências e desafios (Distance education in transition: Trends and Challenges). São Leopoldo: Unisinos.

Rumble, G. (2003). A gestão dos sistemas de ensino a distância (The management of education systems at distance). Brasília: Editora UnB.

Sartori, A., \& Roesler, J. (2005). Educação superior a distância: Gestão da aprendizagem e da produção de materiais didáticos impresso e online (Higher education distance: Learning management and production of printed and online teaching materials). Tubarão: Unisul.

Souza, J. C., \& Faria, M. F. B. (2013). Gestão de sistemas de educação a distância na perspectiva da inovação (Management of distance education systems in the context of innovation). In D. Mil, \& C. Maciel (Eds.), Educação a distância: Elementos para pensar o ensino aprendizagem contemporâneo (Distance education: Elements to think the contemporary teaching learning) (pp. 311-339). Cuiabá: EdUFMT. 